\title{
Вклад гормональных перестроек в проявление защитного действия оксида азота на растения пшеницы при обезвоживании
}

(С) Ч.Р. Аллагулова, А.М. Авальбаев, Д.Р. Масленникова, Р.А. Юлдашев, А.Р. Лубянова, М.В. Безрукова, О.В. Ласточкина, Ф.М. Шакирова

Институт биохимии и генетики УФИЦ РАН

Россия, Республика Башкортостан, 450054 г. Уфра, проспект Октября, 71,

\section{Email: allagulova-chulpan@rambler.ru}

В работе было продемонстрировано защитное и рост-стимулирующее действие оксида азота на растения пшеницы при воздействии обезвоживания. Положительные эфффекты NO могут быть связаны с его влияние на состояние гормональной системы растений пшеницы.

Ключевые слова: оксид азота, пшеница, обезвоживание, устойчивость, фритогормоны.

Засуха принадлежит к наиболее широко распространенным и непредсказуемым экстремальным явлениям, оказывающим негативное действие на все звенья растительного метаболизма, вызывая существенное снижение урожайности сельскохозяйственных культур, включая пшеницу. С целью повышения продуктивности и устойчивости культурных растений к неблагоприятным внешним воздействиям на практике широко применяются химические средства, которые могут представлять серьезную угрозу для окружающей среды и здоровья человека. В качестве альтернативы агрохимикатам интерес представляют природные регуляторы роста, поскольку они являются естественными для растительных организмов соединениями и проявляют свою эффективность в чрезвычайно низких концентрациях, что имеет важное значение для поддержания всеобщей экологической безопасности. Важным природным соединением, вовлекаемым в регуляцию фундаментальных процессов растительного метаболизма, является оксид азота (NO). Он принимает участие в регуляции клеточного цикла растений, прорастания семян, вегетативного роста, морфогенеза, цветения, плодоношения и старения (Карпец и др., 2017; Corpas et al., 2020; Kolbert et al., 2021;). Особый интерес к NO вызван его участием в фрормировании устойчивости растений к разным по природе стрессовым фракторам, включая засуху (Lau et al., 2021). B качестве донора эндогенного NO с целью изучения его эффектов на растения широко применяется нитропруссид натрия (SNP - sodium nitroprusside) (Мамаева и др., 2015). Ранее нами было выявлено, SNP в концентрации 200 мкМ способствует повышению устойчивости растений пшеницы к засолению (Масленникова и др., 2017). Данная работа посвящена исследованию эффректов SNP (200 мкM) на интенсивность ростовых процессов и гормональный статус проростков пшеницы, подвергнутых действию засухи, моделируемой с помощью 12\%гополиэтиленгликоля (ПЭГ).

Объектом исследования служили 4-5 суточные растения пшеницы Triticum aestivum L. сорта Салават Юлаев. 3-суточные проростки предобрабатывали в течение 24 ч раствором 200 мкM SNP. Затем подвергали водному стрессу с использованием неинного осмотика полиэтиленгликоля (ПЭГ) в концентрации $12 \%$. О росте судили по показателям сырой и сухой массы проростков. Количественную оценку свободных фритогормо- 
нов проводили с помощью метода иммуноферментного анализа (Масленникова и др., 2017).

Важным показателем рост-стимулирующего и защитного действия регуляторных соединений являются данные о росте растений. В связи с этим был проведен анализ ростовых параметров проростков пшеницы, предобработанных SNP в норме и при воздействии обезвоживания, моделируемого обработкой ПЭГ. Результаты опытов показали, что предобработка проростков донором NO оказала на них рост-стимулирующее, о чем судили по значениям сырой и сухой массы растений пшеницы. Стрессовая обработка, заметно тормозила рост проростков, что отразилось и на их показателях сырой и сухой массы. Предобработанные SNP и подвергнутые обезвоживанию растения характеризовались существенно меньшим уровнем повреждающего действия стрепсса на показатели роста (Рис. 1). Полученные результаты согласуются с полученными ранее данными о рост-стимулирующем и протекторном действии оксида азота на рост разных видов растений, включая пшеницу (Масленикова и др., 2017; Lau et al., 2021).

(a)

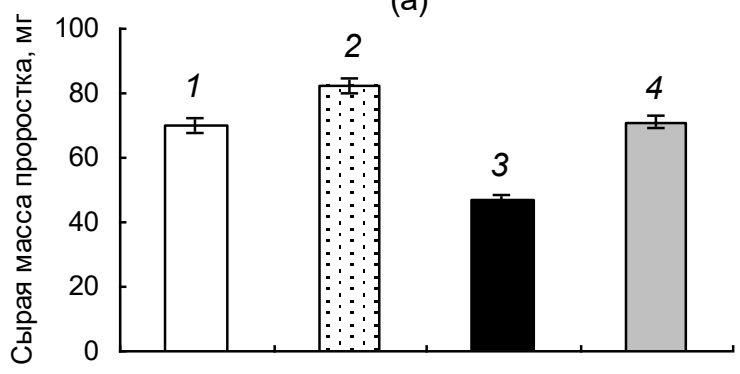

(б)

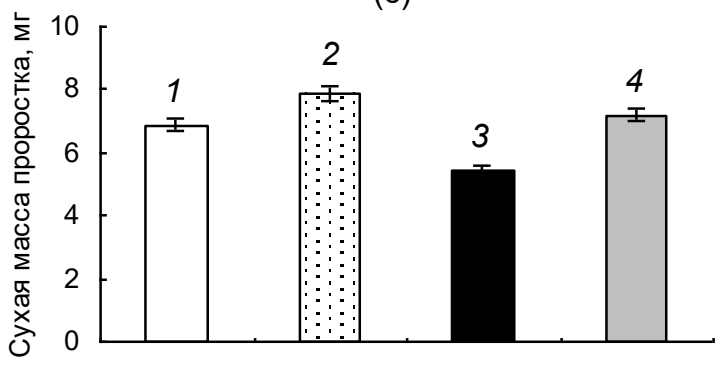

Рис. 1. Показатели сырой (а) и сухой массы (б) 5-суточных проростков предобработанных 200 мкMSNP, подвергнутых воздействию 12\%-ного ПЭГ в течение 24 ч. 1 - Контроль; 2 - SNP; 3 - 12\% ПЭГ; 4 - SNP + 12\% ПЭГ

Рост-стимулирующее и защитное действие оксида азота на растения пшеницы можно объяснить его влиянием на состояние гормональной системы, поскольку ей отводится ведущая роль в регулировании процессов роста и развития растений. В связи с чем важно было провести анализ влияния донороа NO на гормональный статус проростков пшеницы в норме и в условиях моделируемой ПЭГ засухи. Результаты экспериментов показали, что уже к первому часу обработки проростков 200 мкM SNP в нормальных для произрастания условиях наблюдалось двукратное увеличение содержания гормонов цитокининовой природы и некоторое повышение уровня АБК на фоне отсутствия значимых изменений в содержании ИУК. При этом важно подчеркнуть, что повышенный вдвое уровень содержания цитокининов поддерживался в ходе всего опыта (Рис.2). 

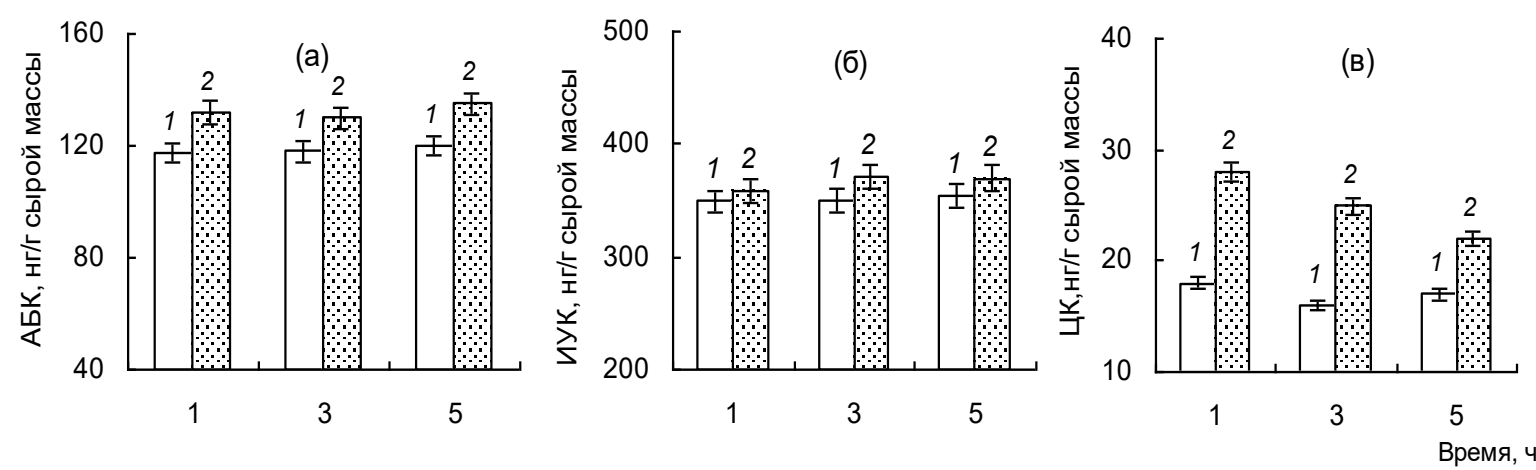

Рис.2. Динамика содержания АБК (а), ИУК (б) и цитокининов (в) в проростках пшеницы в ходе обработки 200 мкM SNP в течение 1, 3, 5 ч в нормальных условиях произрастания. 1 -Контроль; 2 - 200 мкM SNP.
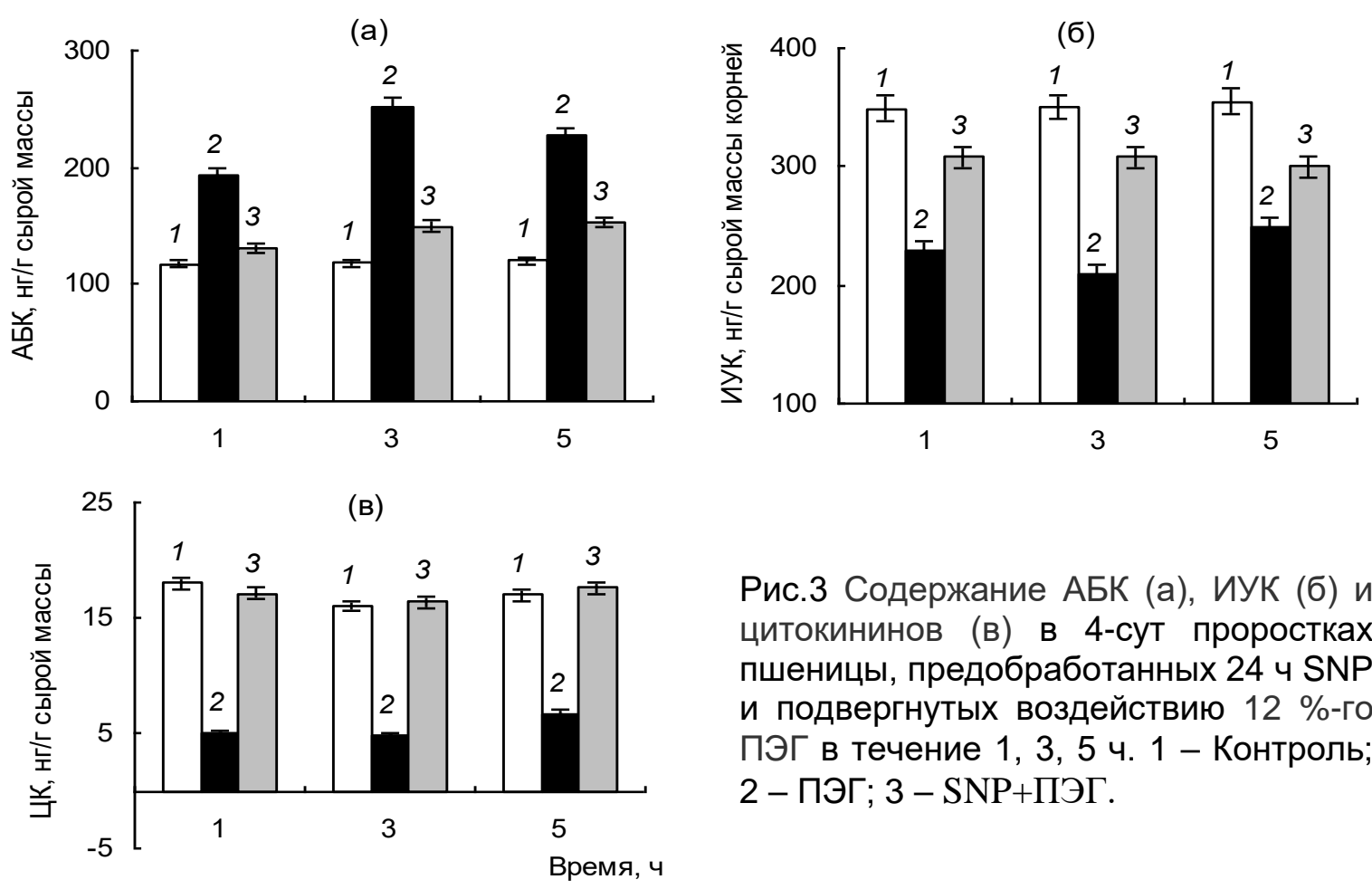

Рис.3 Содержание АБК (а), ИУК (б) и цитокининов (в) в 4-сут проростках пшеницы, предобработанных 24 ч SNP и подвергнутых воздействию $12 \%$-го ПЭГ в течение 1, 3, 5 ч. 1 - Контроль; 2 - ПЭГ; 3 - SNP+ПЭГ.

Обезвоживание вызвало в проростках существенное накопление АБК, снижение содержания ИУК и цитокининов, тогда как SNP-предобработанные и подвергнутые стрессу растения характеризовались снижением уровня стресс-индуцированного накопления АБК, уменьшением падения содержания ИУК, а также и поддержанием концентрации цитокининов на уровне, сопоставимым с контрольными.

Совокупность полученных данных свидетельствуют о том, что донор оксида азота нитропруссид натрия в концентрации 200 мкМ характеризуется сочетаниемт свойств стимулятора роста растений пшеницы и индуктора их устойчивости к условиям обезвоживания, индуцируемого обработкой ПЭГ. Важный вклад в проявление ростстимулирующего и защитного действия оксида азота на растения пшеницы связано с его влиянием на состояние гормональной системы проростков в норме и при обезвоживании. Особого внимание привлекают данные двукратного цитокининов в проростках в ходе их SNP-обработки в нормальных условиях произрастания и предотвраще- 
ния стресс-индуцируемого падения уровня цитокининов в предобработанных SNP растениях пшеницы.

Работа выполнена в рамках госзадания ААAА-А21-121011990120-7 и при поддержке гранта РФФИ № 20-04-00904.

\section{Литература}

1. Corpas F., González-Gordo S., Palma J. Nitric oxide: A radical molecule with potential biotechnological applications in fruit ripening // Journal of Biotechnology. 2020. V. 324. P. 211-219. https://doi.org/10.1016/j.jbiotec.2020.10.020

2. Kolbert Zs., Lindermayr Ch., Loake G. The role of nitric oxide in plant biology: current insights and future perspectives // Journal of Experimental Botany. 2021. V. 72. P. 777-780. https://doi.org/10.1093/jxb/erab013.

3. Lau S. E., Hamdan, M. F., Pua, T. L., Saidi, N. B., Tan, B. C Plant nitric oxide signaling under drought stress // Plants. 2021. V. $10 \quad$ (2). P. 360. https://doi.org/10.3390/plants10020360

4. Карпец Ю.В., Колупаев Ю.Е., Функциональное взаимодействие оксида азота с активными формами кислорода и ионами кальция при формировании адаптивных реакций растений // Вестник харьковского национального университета. 2017. Т. 2. С. 6-31. http://hdl.handle.net/123456789/1333

5. Мамаева А. С., Фоменков А. А., Носов А. В. и др. Регуляторная роль оксида азота у растений // Физиология растений. 2015. Т. 62. С. 459-459. DOI:10.7868/S0015330315040132

6. Масленникова Д. Р., Аллагулова Ч. Р., Федорова К. А., Плотников А. А., Авальбаев А. М., Шакирова Ф. М. Вклад цитокининов в реализацию рост-стимулирующего и протекторного действия оксида азота на растения пшеницы // Физиология растений. 2017. 64(5). C.355-362.

\section{Contribution of hormonal changes to the protective effects of nitric oxide on wheat plants during dehydration}

C.R. Allagulova, A.M. Avalbaev, D.R. Maslennikova, R.A. Yuldashev, A.R. Lubyanova, M.V. Bezrukova, O. V. Lastochkina, F.M. Shakirova

Institute of Biochemistry and Genetics - Subdivision of the Ufa Federal Research Center of the Russian Academy of Sciences

450054 Ufa, Republic of Bashkortostan, Russia, Pr. Oktyabrya, 71,

*Email: allagulova-chulpan@rambler.ru

The protective and growth-stimulating effect of nitric oxide on dehydrated wheat plants has been demonstrated. The positive effects of NO may be related to its effect on the hormonal system of wheat plants.

Key words: nitric oxide, wheat, dehydration, resistance, phytohormones. 